In conclusion, we should like to thank Dr. T. Swarbrick (Long Ashton Research Station), Mr. G. M. Stuart (East of Scotland Agricultural College), and Messrs. Chandler and Dunn (Canterbury), who kindly provided some of the specimens.

East Malling Research Station,

A. Beryl Beakbane.

EleANOR C. THOMPSON.

Kent. May 30.

' Wallace, T., Swarbrick, T., and Ogilvie, L., Grover, 22 (49), 12 (1944)

${ }^{2}$ Crane, M. B., Grower, 22, (53), 10 (1944).

Crane, M. B., Nature, 155, 115 (1945).

- Rendle, B. J., Tropical Woods, 52, 11 (1937).

\section{Pressure Units}

THE recent communication by Dr. W. R. G. Atking ${ }^{1}$ directs attention to a considerable amount of confusion which still exists in statements of numerical results and constants. I suggest that one major change which is desirable is to adopt the bar as the unit of pressure in place of the millimetre of mercury.

In favour of this proposal the following considerations may be advanced: ( 1 ) The bar is an absolute unit $\left(10^{6}\right.$ dyne $\left.\mathrm{cm} .^{-2}\right)$. (2) The unit is already in use, and this use appears to be extending; for example, meteorological readings are expressed in millibars, intensity of sound in dyne $\mathrm{cm} .^{-2}$, compressibility in bar $^{-1}$. (3) In calculations it is often necessary to work in c.G.s. units, involving the conversion of mercury units; for example, in measurements of surface tension or viscosity by methods which involve readings of pressure, and in thermodynamics. (4) The statement of results in terms of the bar avoids the possibility of some degree of indefiniteness when temperature and latitude are not stated, and simplifies statements by removing the necessity for specifying such conditions. (5) The present time presents probably the most favourable opportunity for making such a change, as a large number of new text-books, and revisions of older works, may be expected shortly. (The proposal would fit in with the suggestion made by F. H. Townsend ${ }^{2}$ for a new system of highvacuum units, which could be based on the millibar.)

Against the proposal are the following points. (1) Measurements of pressure are often (but not always) made by means of manometric pressure gauges. (2) A large number of physical and chemical constants are already calculated in terms of mercury pressure.

In answer to the first objection it may be suggested that as, for accurate work, it is necessary in any event to correct for temperature and gravity, no extra labour is involved, since the product of the density of the manometric fluid at a standard temperature and $g$ would be a constant of the apparatus. It would appear to be as easy for an apparatus maker to graduate a mercury gauge in millibars as in millimetres.

With regard to the second point, the constants concerned include: (a) A comparatively small number of important constants, such as the gas constant for particular gases, and related constants, which could be converted very simply; for example, the volume per mol. of a perfect gas becomes 22,712 c.c. at one bar, instead of 22,415 c.c. at $760 \mathrm{~mm}$. (b) A larger number of readings of vapour pressures, etc., where the measured constant is itself a pressure. Pressures given in reference tables would have to be converted to millibars, etc., and this labour might present the chief obstacle to the adoption of the proposal. (c) A very large number of constants, including the International Temperature Scale and tables of boiling-points, the values of which depend on pressure and are given for a specified pressure. In most cases there is no need to recalculate these quantities immediately - they can be quoted for 1.01323 bar instead of for " $760 \mathrm{~mm}$. Hg at $0^{\circ} \mathrm{C}$. and lat. $45^{\circ} . "$

Finally, for approximate conversion from units of mercury pressure to absolute units, it may be noted that 1 bar is equivalent to $750.08 \mathrm{~mm}$. of mercury (approx. $75 \mathrm{~cm}$. - a point which may interest those who teach elementary science).

Science Department,

E. Denne.

Mid-Essex Technical College, Chelmsford.

${ }^{2}$ Atkins, W. R. G., Nature, 155, 361 (1945).

2 Townsend, F. H., Nature, 155, 545 (1945).

\section{The 'Green Flash' at Sunset with a near 'Horizon'}

IT is frequently assumed that the phenomenon of the 'green flash' can be observed only when the sun is seen to rise, or to set behind a distant land- or seahorizon. That such is not the case, the following report of a recent naked-eye observation will confirm.

At $20 \mathrm{~h}$. 12m. U.T. on June 20, 1945, I observed the sun setting behind the horizontal roof-line of a building distant approximately 440 yards from the site of observation. Immediately prior to the disappearance of the last remaining segment of the sun's limb, its colour was seen to change from light orangeyellow, through yellowish-green, to a distinct, but pale, green. At the instant of disappearance I observed the rapidly diminishing bead of sunlight to assume a just perceptible blue-green hue. On account of the large parallax introduced by the short distance from the artificial horizon, it was possible to repeat the observation by standing on tiptoe. The complete sequence of colour changes occurred in a time interval estimated to last from one quarter to one half of one second. It was noted that each of the transient colours was markedly less saturated than those which I had observed against a distant land-horizon on several occasions during the summer of 1940 from the summit of Mount Hamilton, California.

A rough estimate indicated that the altitude of the terrestrial obstacle was rather less than one degree above the true horizon on a bearing due north-west. On the evening in question there was a light southerly wind with a cloud cover of $2 / 10-3 / 10 C i$, the sky in the direction of the sun being entirely free from cloud. Horizontal visibility was excellent; I estimated the range to be in excess of ten miles.

Using an opera-glass to screen off unwanted light, Whitmell ${ }^{1}$ has reported an observation of the green flash with the 'horizon' distant only 300 yards, but I have not been successful in finding any reference to naked-eye observations over so short a range as that recorded in the present note.

45 Briar Road, Kenton,

D. R. BARBER.

Harrow, Middlesex. June 27.

${ }^{1}$ Whitmell, C. T., J. Brit. Ast. As8oc., 12, 289 (1902). 